\title{
Age-appropriate vaccination coverage and its determinants in children aged 12-36 months in Nepal: a national and subnational assessment
}

\author{
Santosh Kumar Rauniyar ( $\square$ rauniyar.sam@gmail.com ) \\ University of Tokyo \\ Yoko Iwaki \\ National Graduate Institute for Policy Studies \\ Daisuke Yoneoka \\ St. Luke's International University \\ Masahiro Hashizume \\ University of Tokyo
}

Shuhei Nomura

Keio University

\section{Research Article}

Keywords: Delay, Timeliness, Vaccine coverage, Vaccination, Immunization

Posted Date: March 5th, 2021

DOI: https://doi.org/10.21203/rs.3.rs-269052/v1

License: (1) This work is licensed under a Creative Commons Attribution 4.0 International License. Read Full License

Version of Record: A version of this preprint was published at BMC Public Health on November 10th, 2021. See the published version at https://doi.org/10.1186/s12889-021-11841-2. 


\section{Abstract}

Background Vaccination is one of the effective ways to develop immunity against potential life-threatening diseases in children in early age. This study is focused on analysing the age-appropriate vaccination coverage at national and subnational levels and identify the factors associated with age-appropriate coverage in Nepal.

Methods 460 children aged 12-36 months were included in the study. The data was obtained from Nepal Demographic and Health Survey (NDHS) 2016-17. Age-appropriate coverage of Bacillus Calmette-Guerin vaccine (BCG), oral polio vaccine (OPV) doses 1-3, pentavalent vaccine (PE) doses 1-3, and first dose of measles, mumps, and rubella vaccine (MMR) were estimated using Kaplan Meier method. Multilevel logistic regression with random intercept was used to identify the factors associated with age-appropriate vaccination.

Results The crude coverage of the vaccines included in the study ranged from $91.5 \%$ (95\% Cl, 88.5-93.7) for PE3 to $97.8 \%$ (95.8-98.7) for BCG. Although the crude coverage of all the vaccines was above $90 \%$, the ageappropriate coverage was significantly low, ranging from $41.5 \%$ (36.5-46.6) for PE3 to $73.9 \%$ (69.2-78.1) for PE1. Furthermore, high disparity in timely vaccination coverage was observed at regional level. Compared to the age-appropriate vaccination coverage in other provinces, Province 2 had the lowest coverage of all, followed by that in Province 6. The timeliness of vaccination was significantly associated with subnational regions i.e., provinces and the season of childbirth.

Conclusion Although the immunization program in Nepal has achieved the target of $90 \%$ crude coverage of all the childhood vaccines, the age-appropriate coverage is significantly low which undermines the effectiveness of the vaccines administered. Thus, along with crude coverage, timeliness of the vaccines administered should be taken into consideration and thoroughly monitored at national and subnational levels. Provincial government should formulate tailored strategies to ensure the timely administration of the childhood vaccines.

\section{Background}

Vaccination is one of the effective ways to develop immunity against potential life-threatening diseases in children in early age. ${ }^{1}$ For instance, diseases such as polio and diphtheria are becoming rare in many countries around the world due to effective and timely vaccination. ${ }^{2,3}$ To reduce the risk of getting exposed to vaccine preventable diseases and to increase immunization coverage of basic childhood vaccines, World Health Organization (WHO) initiated the Expanded Programme on Immunization (EPI) in 1974. Remarkable progress has been made worldwide since the implementation of EPI. ${ }^{4,5}$ For instance, over the last decade, more than 1 billion children have been vaccinated and an estimated 2 to 3 million death has been averted through immunization worldwide. ${ }^{5,6}$ However, at the same time, nearly 20 million children still face insufficient access to vaccines globally. ${ }^{7-9}$ The resurgence of vaccine preventable diseases (VPD) such as measles in Mongolia, USA and in other countries has emphasized that not only coverage rate but also timeliness of the vaccines administered is important to ensure effective immunization. ${ }^{10-13}$

In Nepal, the National Immunization Program (NIP) was implemented in 1979 with the objectives to increase immunization coverage and control the vaccine-preventable diseases. ${ }^{14}$ The immunization programme has 
performed well and has been considered success in recent years. In 2017, the crude vaccination coverage for most of the vaccines was reported above $80 \% .{ }^{15}$ However, the increasing cases of measles and high prevalence of tuberculosis in Nepal in recent years has posed an important question on the effectiveness of the immunization program. ${ }^{16,17}$ Currently, the surveillance report on immunization by WHO emphasized that the immunization program is solely focused on attaining high coverage rate while neglecting the timeliness of the vaccines administered. ${ }^{15}$. Delay in immunizations may cause outbreaks of infectious disease since vaccines delivered outside the immunization schedule leave temporal gaps in immunity in which children are vulnerable to infections. ${ }^{18}$ Hence, to realize the full benefits of immunization program, it is important to consider timely administration of the vaccines along with the high coverage rate. However, there are no studies been conducted at national level to access the timeliness of childhood vaccines in Nepal. Thus, this is the first study aimed to analyse the age-appropriate vaccination coverage at national and subnational levels and to identify the factors associated with age-appropriate vaccination in Nepal.

\section{Method}

\section{Data source}

We used recently available data from Nepal Demographic and Health Survey, (NDHS) 2016-17. NDHS is a nationally representative population-based cross-sectional household surveys that included information about maternal and child health. Data were collected from June 2016 to January 2017. Out of 11,472 occupied households 11,203 were interviewed with response rate of $99.0 \%$. The survey used multistage stratified cluster sampling design method to collect the data. The questionnaire for children under five was administered to mothers (or caretakers) of the children through women's questionnaire. In total 6,091 children under five years were selected with the response rate of $98.6 \%$. The details of sampling methods and questionnaires are described elsewhere. ${ }^{19}$.

\section{Study population}

Initially, 514 children aged 12-36 months were included in the study. Out of 514 children, 54 of them, who did not have mother or child health books or vaccination cards, which are official written records of vaccination history provided by Government of Nepal, ${ }^{14}$ were excluded. For the final analyses, 460 children were included in the study.

\section{Vaccines}

The Vaccines assessed in this study were Bacillus Calmette-Guerin vaccine (BCG); Oral polio, doses 1-3 (OPV1, OPV2, and OPV3); Pentavalent vaccine (DTP-Diphtheria, Tetanus, and Pertussis vaccine; Hep B Hepatitis B vaccine; Hib-Hemophilus influenzae type b vaccine), doses 1-3 (PE1, PE2, and PE3); and Measles, mumps, and rubella vaccine first dose (MMR1) (Table 1).

Crude and age-appropriate vaccine coverage

The proportion of children who received the routine vaccines regardless of the age at which they received the vaccine was considered as crude vaccine coverage. 
The age-appropriate vaccination was defined as children who received a vaccine dose within the recommended age according to the immunization schedule of National immunization Programme (NIP) Nepal, (Table 1), ${ }^{14}$ plus 30 days grace period after the due date. The grace period for age-appropriate vaccination was decided based on previous studies. ${ }^{20,21}$ The administration date of the vaccines was calculated by subtracting the date of birth from the date of the vaccination. Children receiving the vaccines after the recommended age-range were considered to have received delayed vaccination. Vaccines administered before the recommended age-range was defined as early vaccination. Children who had been marked as not given vaccines or marked as given vaccines, but no date found on the mother and child health book or vaccination card were considered as children not vaccinated.

\section{Statistical analysis}

The proportion of crude and age-appropriate vaccine coverage with $95 \%$ confidence interval (Cl) were calculated for each vaccine dose at national and regional levels. To analyse the timeliness of the vaccines administered according to the immunization schedule of NIP Nepal, we used Kaplan-Meier product limit method. Due to the multi-stage sampling method, all the analyses were adjusted to the sampling weight.

Next, we used multivariate logistic regression to investigate the association between age-appropriate vaccination and socioeconomic variables, as well as characteristics of the children and their parents, including gender of the children, mothers' age, mothers' education, socio-economic status of households, religion of household heads, ethnicity, area of residence, mothers' occupation, and season of childbirth. To select the covariates, we used the backward stepwise variable selection method with cut-off level at $p<0.05$. The regression models included random effects at cluster levels to control for correlation among different clusters. The restricted maximum likelihood method was used to estimate the regression parameters. $P$ value $<0.05$ was considered for statistical significance. STATA/SE 15.1 and R programming were used to analyse the data and create geospatial mapping.

We used the STROBE cross-sectional reporting guidelines, the standard guidelines to report cross-sectional study. 22

\section{Results}

\section{Sample characteristics}

460 eligible children aged between 12-36 months were included in the analyses: $54.6 \%(n=251)$ were male, $54.4 \%$ (250) children had mothers aged between 25 and 44 years and $56.2 \%$ (258) children had mothers having secondary school or higher education background (Table 2). Out of total sample population, $46.2 \%$ (213) belonged to Dalit and Janjati ethnicity and 44.5\% (205) lived in rural areas. $70.4 \%$ of mothers had antenatal visit more than three times during the pregnancy. (Table 2).

\section{Crude and age-appropriate vaccine coverage}


The crude vaccination coverage ranged from 91.5\% (95\% Cl, 88.5-93.7) for PE3 to 97.8\% (95.8-98.7) for BCG. Although the crude coverage of all the vaccines was above $90 \%$, the age-appropriate coverage was significantly low ranging from 41.5\% (36.5-46.6) for PE3 to 73.9 \% (69.2-78.1) for PE1. (Table 3)

Figure 1 and figure 3 show the age-appropriate coverage of BCG, vaccine at national and regional level. As shown in figure 1 and table $3,54.6 \%(95 \% \mathrm{Cl}$, 49.3-59.7) of the children were vaccinated for $\mathrm{BCG}$ within the recommended age-range. At regional level, Province 3 has the highest age-appropriate coverage that was 73.3\% (59.6-83.6) followed by Province 4 that was 70.7\% (56.8-81.7). Province 2 had the lowest ageappropriate BCG coverage which was 31.9\% (20.4-46.0) followed by Province 6, 44.9\% (25.5-65.9) (Figure 3).

For the MMR1 vaccine, 53.8\% (95\% Cl, 48.5-59.0) of the children were vaccinated within the recommended age-range (Figure 1 and table 3). The proportion of delayed vaccination was 31.2\% (30.3-40.4) (Table 3). At regional level, Province 4 has the highest age-appropriate coverage for MMR1 vaccine 65.4\% (51.1-77.4) followed by Province 6, 63.3\% (39.3-82.1). Similar to OPV and PE vaccine, Province 2 has the lowest ageappropriate coverage for MMR1, 36.1\% (24.3-49.9) (Figure 3).

Figure 2 and figure 4 shows the age-appropriate coverage of OPV1-OPV3 (OPV1, OPV2, and OPV3) vaccines received by children over time at national and regional levels. As shown in figure 2 and Table 3, for the OPV1 vaccine $73.13 \%(95 \% \mathrm{Cl}, 68.3-77.5)$ of the children received it at recommended age. For OPV second and third doses (OPV2 and OPV3) these number were 60.1\% (54.9-65.1) and 41.7\% (36.7-46.9), respectively. The proportions of delayed vaccination for OPV1, OPV2, and OPV3 were 21.8\% (17.9-26.4), 38.1\% (33.2-43.2), and $57.9 \%$ (52.7-62.9) respectively (Table 3). At regional level, Province 4 has the highest age-appropriate coverage of OPV1, and OPV2 while Province 3 has highest age-appropriate coverage of OPV3 vaccines. Province 2 has the lowest age-appropriate coverage for all doses of OPV vaccine (Figure 4).

Figure 2 and figure 5 presents children who received age-appropriate PE1-PE3 (PE1, PE2, and PE3) vaccines over time at national and regional levels. For PE1-PE3 vaccines, 73.9\% (95\% Cl, 69.2-78.1), 60.6\% (55.6-65.4), and $41.2 \%$ (36.5-46.6) children were vaccinated within the recommended age-range respectively (Table 3$)$. The proportions of delayed vaccination for PE1, PE2, and PE3 were 21.4\% (17.5-25.8), 37.8\% (33.1.7-42.9), and $58.4 \%$ (53.3-63.3). At regional level, Province 4 has the highest age-appropriate coverage for the first dose of pentavalent vaccine; 84.9 (72.4-92.3) followed by Province 3; 84.3 (72.9-91.5). Province 3 had highest ageappropriate coverage of second and third doses of pentavalent vaccine; 72.5\% (60.0-82.2), and 57.0 (44.168.9) respectively. Province 2 has the lowest age-appropriate coverage for all the doses of PE vaccine among all (Figure 5).

Factors associated with age-appropriate vaccination of BCG, OPV1-OPV3, PE1-PE3 and MMR vaccines 
The significant results from multilevel logistic regression models are shown in Table 4 and table 5. The regression analysis showed that the children born in spring and winter had significantly higher odds of receiving age-appropriate $B C G$ vaccines (odds ratio [OR], 2.34, 95\% Cl, 1.21-4.54) for spring, $(3.86,1.83-8.13)$ for winter compared to those born in summer. Children in Province 2 and Province 6 have significantly lower odds of receiving timely vaccination for BCG, OPV1, OPV2, PE1, and PE2 compared to children in other provinces. (Table 4 and table 5). Other factors did not show significant association.

\section{Discussion}

Full benefits of vaccination could be attained through high coverage and timely administration. Nepal has already met the immunization target set by WHO to attain $90 \%$ coverage for most of the childhood vaccines. The 2018 annual report provided by the Health Ministry of Nepal, states that the crude coverage of all most all the vaccines were above $90 \%$. The crude coverage reported for some vaccines such as BCG was $98 \%$ which aligns with our study result. ${ }^{15}$ However, according to our study findings, the age appropriate coverage of these vaccines is significantly low. For instance, the age-appropriate coverage of BCG vaccine is below $60 \%$ at national level.

Although immunization program has been considered successful in Nepal with target coverage being met, ${ }^{23}$ low age-appropriate coverage of these vaccines remains a big issue. Several studies conducted in similar settings in different countries estimated low age-appropriate coverage of childhood vaccines. ${ }^{12,20,24-27}$ The recent increase in number of measles and tuberculosis cases in Nepal could be attributed to untimely vaccination in Nepal. ${ }^{17,28}$ The reasons behind the low age-appropriate vaccines coverage rate might include a lack of awareness about the immunization schedule, low socio-economic status, hard to access health care facilities, reluctancy in administering vaccines, hesitancy of parents regarding vaccination, insufficient infrastructure to transport and store the vaccine in hard to reach areas, and occurrence of unusual events such as natural disaster, disease outbreak (pandemic situation). ${ }^{20,26,27,29-33}$

The huge earthquake of 2015 in Nepal significantly affected the healthcare services in different provinces throughout the country. ${ }^{34}$ Our study was conducted after the earthquake. Therefore, it is highly possible the 2016 earthquake could have a significant effect on health care facilities and leading to delay in vaccination and resulting in low age-appropriate coverage. Similar to that situation, it could be inferenced that the Covid19 outbreak would affect the vaccination program in different regions and would increase the risk to the resurgence of VPD. ${ }^{35}$ Therefore, to cope with the unforeseen circumstances such as natural disasters and disease outbreaks, the central government along with the local government should focus on capacity building for disaster preparedness, improve basic infrastructure, mostly in hard to reach areas, and strengthen community healthcare facilities. Furthermore, the provincial governments should focus on planning and setting framework based on the local situation at regional levels.

In this study we found that along with low age-appropriate coverage, the timely coverage of later doses of vaccines subsequently declines compared to the former doses. For instance, timely coverage of second and third doses of OPV and PE vaccines significantly decreases as compared to its respective first dose. This result is similar to those found in the neighbouring countries such as Bangladesh and Pakistan. ${ }^{26,36}$ One of the 
possible explanations for this could be the increasing workload of mothers and increase in domestic activities while the child became older. Another explanation could be the adverse events such as fever, pain or swelling on the injection site, following the prior doses that would restrain mothers for the next appointment. ${ }^{37,38}$ Furthermore, parents' perception that the later doses are not as important as the first dose, and reluctancy to follow up could explain the existing low age-appropriate coverage for later doses. ${ }^{29,38}$

At regional level, high disparity was observed in the age-appropriate vaccination coverage. In Province 2 and Province 6 the timely vaccination coverage was lower compared to that in other regions. Though, geographically Province 2 is easily accessible, the lower vaccination coverage could be due to low literacy rate, hesitancy towards vaccination, knowledge and attitude about the immunization program, lack of proper health care infrastructure in rural areas, and other cultural barriers. ${ }^{39-41}$ In case of Province 6 the lower age appropriate coverage could be due to hard to reach terrain, lack of awareness about the immunization schedule, lack of sufficient infrastructure such as transportation and storage facilities, and lack of human

resource in health sector. ${ }^{32,33}$ Province 3 had the highest coverage of almost all the vaccines as it is the central region with most of the areas urbanized and developed. ${ }^{19,41}$

As highlighted in the previous study ${ }^{20}$, the analysis of vaccine data using the DHS has several limitations. First, only children who had vaccination records in the mother and child health book (the vaccination card) were included. Exclusion of children without vaccination records might lead to overestimation of the vaccination coverage and timeliness if these children were less likely to receive adequate vaccinations.

Children who were excluded from our analyses due to missing data on vaccination were more likely to be from the poorest household as compared with those included in the study. Second, age-appropriate vaccination coverage among children can be influenced by many other factors, including those related to access to health care services, knowledge, attitudes, and practices of parents and providers. The variables investigated in this study were limited to those available in DHS. Third, due to significant missing data and long administration period (between 4 to 6 years of age) of second dose of MMR vaccines we could not include it in the study. Finally, both early and delayed vaccinations were analyzed as a single category. Investigation of each of these types of untimely vaccinations is a topic for future studies.

\section{Conclusion}

This is the first national level study conducted in Nepal focusing on the timeliness of childhood vaccination. Our study showed that although the crude coverage of childhood vaccines is above $90 \%$, the age-appropriate coverage of these vaccines is significantly low at national and subnational levels. The national immunization program is solely focused on attaining high crude coverage while neglecting the importance of timeliness of the vaccines administered. The significantly low age-appropriate coverage of all the childhood vaccines at national and subnational level emphasizes the importance of formulating effective policies at national and subnational levels to improve the age-appropriate coverage rate. Increased focus on promoting awareness about the immunization schedule in several regions, particularly, in the provinces with significantly low ageappropriate coverage (Province 2 and Province 6) is of prime importance. This could be done through the use of smart phone/mobile phones (mHealth), which has been effective strategy to improve vaccination coverage in several countries. ${ }^{42,43}$ Promoting and strengthening community healthcare facilities is important to reduce 
the negative impact of unforeseen circumstances such as the natural disasters and disease outbreaks on the immunization program.

\section{List Of Abbreviations}

BCG

$\mathrm{Cl}$

DPT

EPI

Hep B

Hib

MMR

NDHS

NIP

OPV

PE

VPD

WHO
Bacillus Calmette-Guerin Vaccine

Confidence interval

Diphtheria, Tetanus and Pertussis Vaccine

Expanded Programme on Immunization

Hepatitis B Vaccine

Hemophilus Influenza Type b Vaccine

Measles, Mumps, and Rubella Vaccine

Nepal Demographic and Health Surveys

National Immunization Program

Oral polio Vaccine

Pentavalent Vaccine

Vaccine Preventable Diseases

World Health Organization

\section{Declarations}

\section{Ethics approval and consent to participate:}

Ethical Approval Nepal obtained from Institutional Review Board, ICF International. Nepal ICF Project Number: 132989.0.000.NP.DHS.01

\section{Consent for application}

Not applicable

\section{Availability of data and materials}

The datasets analyzed during the study are available in the Demographic and Health Surveys, DHS repository, https://dhsprogram.com/data/dataset/Nepal_Standard-DHS_2016.cfm?flag=0

\section{Competing interest}


The authors have declared that no competing interests exist.

\section{Funding}

None.

\section{Author contributions}

All authors were responsible for the study concept and design. Santosh Kumar Rauniyar acquired the data. Santosh, Santosh Kumar Rauniyar, Yoko Iwaki, Daisuke Yoneoka, and Shuhei Nomura analyzed and interpreted the data. Santosh Kumar Rauniyar conducted statistical analysis and drafted the article. Masahiro Hashizume and Shuhei Nomura supervised the research. All authors made critical revision of the manuscript for important intellectual content and gave final approval for the manuscript.

\section{Acknowledgements}

We thank Professor Jeevan Bahadur Sherchadn and Ms. Aya Ishijuka for giving us utmost assistance and valuable suggestions.

\section{References}

1. National Center for Immunization and Respiratory Diseases, CDC. Vaccines and Prevantable Diseases. 2016. https://www.cdc.gov/vaccines/vpd/index.html (accessed August 2020).

2. Andre FE, Booy R, Bock HL, et al. Vaccination greatly reduces disease, disability, death and inequity worldwide. Bulletin of the World Health Organization 2008; 86(2): 140-6.

3. Reid M, Fleck F. The immunization programme that saved millions of lives. Bulletin of the World Health Organization 2014; 92(5): 314-5.

4. Keja K, Chan C, Hayden G, Henderson RH. Expanded programme on immunization. World Health Stat $Q$ 1988; 41(2): 59-63.

5. World Health Organization. Immunization Coverage 2020. https://www.who.int/news-room/factsheets/detail/immunization-coverage (accessed 10 September, 2020).

6. Unicef. UNICEF Data: Monitoring the situation of children and women. 2020. https://data.unicef.org/topic/child-health/immunization/ (accessed 10 September 2020).

7. WHO/UNICEF. Coverage estimates and estimation of number of children vaccinated or not vaccinated 2016 ed: WHO/UNICEF; 2016.

8. Ryman TK, Dietz V, Cairns KL. Too little but not too late: results of a literature review to improve routine immunization programs in developing countries. BMC Health Serv Res 2008; 8: 134.

9. World Health Organization Vaccines and Immunization 2019. https://www.who.int/healthtopics/vaccines-and-immunization\#tab=tab_1 (accessed 15 September 2020). 
10. Centers for Disease Control and Prevention. Risks of Delaying or Skipping Vaccines. 2019. https://www.cdc.gov/vaccines/parents/why-vaccinate/risks-delaying-vaccines.html (accessed 12 September 2020).

11. Walton S, Cortina-Borja M, Dezateux C, et al. Measuring the timeliness of childhood vaccinations: Using cohort data and routine health records to evaluate quality of immunisation services. Vaccine 2017; 35(51): 7166-73.

12. Tsega A, Hausi H, Chriwa G, Steinglass R, Smith D, Valle M. Vaccination coverage and timely vaccination with valid doses in Malawi. Vaccine Reports 2016; 6: 8-12.

13. Hughes MM, Katz J, Englund JA, et al. Infant vaccination timing: Beyond traditional coverage metrics for maximizing impact of vaccine programs, an example from southern Nepal. Vaccine 2016; 34(7): $933-41$.

14. Ministry of Health and Population, Government of Nepal. National Immunization Programme 2020. https://www.mohp.gov.np/eng/program/child-health-services/nip (accessed 20 September 2020).

15. Department of Health Services, Ministry of Health and Population, Government of Nepal. Annual Report 2018. Kathmandu: Ministry of Health and Population, Government of Nepal, 2017/18.

16. UNICEF Nepal. Over 20 million children worldwide missed out on measles vaccine annually in past 8 years, creating a pathway to current global outbreaks. UNICEF; 2019.

17. National TB Control Centre, Government of Nepal, Ministry of Health and Population. TB Burden in Nepal : Nepal National TB Prevalence Survey Brief: Ministry of Health and Population, Government of Nepal and World Health Organization, 2020.

18. Haider EA, Willocks LJ, Anderson N. Identifying inequalities in childhood immunisation uptake and timeliness in southeast Scotland, 2008-2018: A retrospective cohort study. Vaccine 2019; 37(37): 5614-24.

19. Ministry of Health $\mathrm{MOH}$, New ERAN, Icf. Nepal Demographic and Health Survey 2016. Kathmandu, Nepal: MOH/Nepal, New ERA, and ICF, 2017. http://dhsprogram.com/pubs/pdf/FR336/FR336.pdf

20. Rauniyar SK, Munkhbat E, Ueda P, Yoneoka D, Shibuya K, Nomura S. Timeliness of routine vaccination among children and determinants associated with age-appropriate vaccination in Mongolia. Heliyon 2020; 6(9).

21. Babirye JN, Engebretsen IMS, Makumbi F, et al. Timeliness of Childhood Vaccinations in Kampala Uganda: A Community-Based Cross-Sectional Study. PLOS ONE 2012; 7(4): e35432.

22. Elm Ev, Altman DG, Egger M, Pocock SJ, Gøtzsche PC, Vandenbroucke JP. Strengthening the reporting of observational studies in epidemiology (STROBE) statement: guidelines for reporting observational studies. BMJ 2007; 335(7624): 806-8.

23. Acharya $K$, Paudel YR, Dharel $D$. The trend of full vaccination coverage in infants and inequalities by wealth quintile and maternal education: analysis from four recent demographic and health surveys in Nepal. BMC Public Health 2019; 19(1): 1673.

Page 10/22 
24. Tao W, Petzold M, Forsberg BC. Routine vaccination coverage in low- and middle-income countries: further arguments for accelerating support to child vaccination services. Global Health Action 2013; 6(1): 20343.

25. Sreevatsava M, Burman AL, Wahdan A, et al. Routine immunization coverage in Pakistan: a survey of children under 1 year of age in community-based vaccination areas. Vaccine 2020; 38(28): 4399-404.

26. Sheikh N, Sultana M, Ali N, et al. Coverage, Timelines, and Determinants of Incomplete Immunization in Bangladesh. Trop Med Infect Dis 2018; 3(3): 72.

27. Choudhary TS, Reddy NS, Apte A, et al. Delayed vaccination and its predictors among children under 2 years in India: Insights from the national family health survey-4. Vaccine 2019; 37(17): 2331-9.

28. World Health Organization. WHO vaccine-preventable diseases: monitoring system. 2020 global summary. 2020. https://apps.who.int/immunization_monitoring/globalsummary/incidences?c=NPL (accessed September 20, 2020 2020).

29. Dubé $E$, Vivion $M$, MacDonald NE. Vaccine hesitancy, vaccine refusal and the anti-vaccine movement: influence, impact and implications. Expert Rev Vaccines 2015; 14(1): 99-117.

30. Sibeudu FT, Uzochukwu BSC, Onwujekwe OE. Rural-urban comparison of routine immunization utilization and its determinants in communities in Anambra States, Nigeria. SAGE Open Medicine 2019; 7: 2050312118823893.

31. Esposito S, Principi N, Cornaglia G. Barriers to the vaccination of children and adolescents and possible solutions. Clinical Microbiology and Infection 2014; 20: 25-31.

32. Parajuli J, Haynes KE. Transportation network analysis in Nepal: a step toward critical infrastructure protection. Journal of Transportation Security 2018; 11(3): 101-16.

33. Preeti KM, Giridhari Sharma P. Access to free health-care services for the poor in tertiary hospitals of western Nepal: a descriptive study. WHO South-East Asia Journal of Public Health 2015; 4(2): 167-75.

34. Goyet S, Rayamajhi R, Gyawali BN, et al. Post-earthquake health-service support, Nepal. Bull World Health Organ 2018; 96(4): 286-91.

35. Mathema S. The impact of COVID-19 on Immunization Services. Journal of Lumbini Medical College 2020; 8(1): 158-60.

36. Noh J-W, Kim Y-m, Akram N, et al. Determinants of timeliness in early childhood vaccination among mothers with vaccination cards in Sindh province, Pakistan: a secondary analysis of cross-sectional survey data. BMJ Open 2019; 9(9): e028922.

37. Marefiaw TA, Yenesew MA, Mihirete KM. Age-appropriate vaccination coverage and its associated factors for pentavalent 1-3 and measles vaccine doses, in northeast Ethiopia: A community-based cross-sectional study. PloS one 2019; 14(8): e0218470-e. 
38. Chambongo PE, Nguku P, Wasswa P, Semali I. Community vaccine perceptions and its role on vaccination uptake among children aged 12-23 months in the lleje District, Tanzania: a cross section study. The Pan African medical journal 2016; 23: 162-.

39. Ministry of Health. Nepal Demographic and Health Survey 2016. In: Nepal MoH, editor. Kathmandu, Nepal: New ERA and ICF; 2017.

40. Song $\mathrm{IH}$, Palley E, Atteraya MS. Inequalities in complete childhood immunisation in Nepal: results from a population-based cross-sectional study. BMJ Open 2020; 10(9): e037646.

41. Government of Nepal. Nepal Living Standard Survey 2010/11. Central Bureau of Statistics, National Planning Commission Secretriat Website, Government of Nepal. 2011.

http://cbs.gov.np/nada/index.php/catalog/37/study-description (accessed September 20, 2020 2020).

42. Kazi AM. The role of mobile phone-based interventions to improve routine childhood immunisation coverage. The Lancet Global Health 2017; 5(4): e377-e8.

43. Dumit EM, Novillo-Ortiz D, Contreras M, Velandia M, Danovaro-Holliday MC. The use of eHealth with immunizations: An overview of systematic reviews. Vaccine 2018; 36(52): 7923-8.

\section{Tables}

Table 1: The national immunization schedule, Nepal ${ }^{14}$

\begin{tabular}{|llllll|}
\hline Name of vaccines & $\begin{array}{l}\text { At birth } \\
\text { (at 0-30 } \\
\text { day) }\end{array}$ & $\begin{array}{l}\text { 6 weeks of } \\
\text { age (at 42- } \\
\mathbf{7 2} \text { day) }\end{array}$ & $\begin{array}{l}10 \text { weeks of } \\
\text { age (at 70 } \\
-100 \text { day) }\end{array}$ & $\begin{array}{l}14 \text { weeks of } \\
\text { age (at 91- } \\
121 \text { day) }\end{array}$ & $\begin{array}{l}9 \text { months of } \\
\text { age (at 274- } \\
\mathbf{3 0 4} \text { day) }\end{array}$ \\
\hline BCG & BCG0 & & & & \\
OPV & & OPV1 & OPV2 & OPV3 & \\
$\begin{array}{l}\text { Pentavalent (DPT, Hep } \\
\text { B, and Hib) }\end{array}$ & & Penta1 & Penta2 & Penta3 & \\
\hline MMR & & & & & MMR 1 \\
\hline
\end{tabular}

BCG-Bacillus Calmette-Guerin vaccine; OPV-Oral Polio vaccine; DTP-Diphtheria, Tetanus, and Pertussis vaccine; Hep B Hepatitis B vaccine; Hib-Hemophilus influenzae type b vaccine; MMR-Measles, Mumps, and Rubella vaccine; numbers indicate a dose order.

\section{Table 2: Sample characteristic of 460 children aged 12-36 months, in Nepal, 2016.}




\begin{tabular}{|c|c|c|}
\hline Variables & Number & Proportion (\%) \\
\hline \multicolumn{3}{|l|}{ Gender } \\
\hline Male & 251 & 54.6 \\
\hline Female & 209 & 45.4 \\
\hline \multicolumn{3}{|l|}{ Mother's age } \\
\hline $15-24$ & 210 & 45.6 \\
\hline $25-34$ & 218 & 47.4 \\
\hline $35-44$ & 32 & 7.0 \\
\hline \multicolumn{3}{|l|}{ Mother's education } \\
\hline No formal education & 104 & 22.6 \\
\hline Primary level education & 98 & 21.2 \\
\hline Secondary level education & 172 & 37.5 \\
\hline Higher education & 86 & 18.7 \\
\hline \multicolumn{3}{|l|}{ Ethnicity } \\
\hline Bhrahmin/Chettri & 142 & 30.8 \\
\hline Dalit and Janjati & 213 & 46.2 \\
\hline Newar & 18 & 3.9 \\
\hline Muslim & 18 & 4.1 \\
\hline Others & 69 & 15.0 \\
\hline \multicolumn{3}{|l|}{ Area of residence } \\
\hline Urban & 255 & 55.5 \\
\hline Rural & 205 & 44.5 \\
\hline \multicolumn{3}{|l|}{ Province } \\
\hline Province 1 & 72 & 15.6 \\
\hline Province 2 & 78 & 16.9 \\
\hline Province 3 & 83 & 18.2 \\
\hline Province 4 & 57 & 12.4 \\
\hline Province 5 & 102 & 22.1 \\
\hline Province 6 & 28 & 5.9 \\
\hline Province 7 & 40 & 8.9 \\
\hline
\end{tabular}




\begin{tabular}{|lll|}
\hline Winter & 139 & 30.2 \\
\hline Spring & 120 & 26.1 \\
\hline Summer & 100 & 21.7 \\
\hline Autumn & 101 & 22.0 \\
\hline ANC visits & & \\
\hline Not visited & 15 & 3.4 \\
\hline Visited once & 13 & 2.9 \\
\hline Visited twice & 22 & 4.6 \\
\hline Visited 3 times & 47 & 10.1 \\
\hline Visited more than 3 times & 324 & 70.4 \\
\hline Missing & 39 & 8.6 \\
\hline
\end{tabular}

ANC-Antenatal care. The given sample size is adjusted to the survey sample weight.

Table 3: Crude and age-appropriate vaccination coverage in Nepal $(n=460)$ 


\begin{tabular}{|c|c|c|c|c|}
\hline Vaccines & $\begin{array}{l}\text { Crude } \\
\text { coverage }\end{array}$ & $\begin{array}{l}\text { Age- } \\
\text { appropriate } \\
\text { coverane }\end{array}$ & $\begin{array}{l}\text { Early } \\
\text { vaccination }\end{array}$ & $\begin{array}{l}\text { Delayed } \\
\text { vaccination }\end{array}$ \\
\hline & $\begin{array}{l}\text { Proportion (95\% } \\
\mathrm{Cl})\end{array}$ & Proportion $(95 \% \mathrm{Cl})$ & Proportion, $95 \% \mathrm{Cl}$ & Proportion, $95 \% \mathrm{Cl}$ \\
\hline BCG & $\begin{array}{l}97.77(95.85- \\
98.75)\end{array}$ & $54.58(49.33-59.73)$ & - & $45.41(40.26-50.67)$ \\
\hline OPV1 & $\begin{array}{l}96.19(94.00- \\
97.60)\end{array}$ & $73.13(68.31-77.46)$ & $5.03(3.20-7.84)$ & $21.83(17.86-26.39)$ \\
\hline OPV2 & $\begin{array}{l}95.56(93.23- \\
97.10)\end{array}$ & $60.13(54.97-65.07)$ & $1.82(0.85-3.86)$ & $38.05(33.17-43.18)$ \\
\hline OPV3 & $\begin{array}{l}94.38 \text { (91.86- } \\
96.16)\end{array}$ & $41.74(36.72-46.93)$ & $0.36(0.06-2.00)$ & $57.91(52.71-62.94)$ \\
\hline Penta1 & $\begin{array}{l}97.69 \text { (95.83- } \\
98.73)\end{array}$ & $73.94(69.24-78.14)$ & $4.70(2.97-7.38)$ & $21.35(17.49-25.80)$ \\
\hline Penta2 & $\begin{array}{l}97.21(95.22- \\
98.38)\end{array}$ & $60.61(55.56-65.44)$ & $1.56(0.69-3.46)$ & $37.83(33.05-42.86)$ \\
\hline Penta3 & $\begin{array}{l}91.49(88.55- \\
93.73)\end{array}$ & 41.48 (36.54-46.59) & - & $58.38(53.26-63.31)$ \\
\hline MMR1 & $\begin{array}{l}96.15(93.94- \\
97.57)\end{array}$ & $53.83(48.53-59.04)$ & $11.00(8.10-14.77)$ & $35.17(30.30-40.38)$ \\
\hline
\end{tabular}

Cl-Confidence interval; BCG-Bacillus Calmette-Guerin vaccine; OPV-Oral Polio vaccine; DTP-Diphtheria, Tetanus, and Pertussis vaccine; Hib-Haemophilus influenzae type b vaccine; MMR-Measles, Mumps, and Rubella vaccine; numbers indicate a dose order.

Table 4: Multilevel logistic regression results for BCG and MMR1 vaccine $(n=460)$ 


\begin{tabular}{|lll|}
\hline Variables & \multicolumn{2}{l|}{ Odds ratio $(95 \% \mathrm{Cl})$ for age-appropriate vaccination } \\
\hline Province & BCG & MMR1 \\
\hline Province 3 & $1.00\left(\mathrm{ref}^{1}\right)$ & $1.00(\mathrm{ref})$ \\
\hline Province 1 & $0.53(0.19-1.47)$ & $0.66(0.21-2.07)$ \\
\hline Province 2 & $0.21(0.07-0.67)^{\star \star}$ & $1.42(0.40-5.05)$ \\
\hline Province 4 & $0.82(0.29-2.31)$ & $0.55(0.17-1.77)$ \\
\hline Province 5 & $0.31(0.11-0.85)^{\star}$ & $0.90(0.29-2.76)$ \\
\hline Province 6 & $0.28(0.09-0.88)^{\star}$ & $0.57(0.17-1.90)$ \\
\hline Province 7 & $0.70(0.24-2.05)$ & $0.86(0.27-2.71)$ \\
\hline Season of childbirth & & \\
\hline Summer & $1.00($ ref) & $1.00($ ref $)$ \\
\hline Spring & $2.34(1.21-4.54)^{\star}$ & $1.21(0.56-2.60)$ \\
\hline Autumn & $1.63(0.81-3.27)$ & $1.46(0.66-3.23)$ \\
\hline Winter & $3.86(1.83-8.13)^{\star \star \star *}$ & $1.84(0.81-4.19)$ \\
\hline
\end{tabular}

Cl- Confidence interval; ref-reference; BCG-Bacillus Calmette-Guerin vaccine; MMR-Measles, Mumps, and Rubella vaccine; ${ }^{*}<0.05 ; * \star p<0.01 ; p<0.001$; Random effect at PSU level was incorporated to account for survey design.

Table 5: Multilevel logistic regression results for OPV1-OPV3 and PE1-PE3 $(n=460)$ 


\begin{tabular}{|c|c|c|c|c|c|c|}
\hline \multirow[t]{2}{*}{ Variables } & \multicolumn{6}{|c|}{ Odds ratio $(95 \% \mathrm{Cl})$ for age-appropriate vaccination } \\
\hline & OPV1 & OPV2 & OPV3 & PE1 & PE2 & PE3 \\
\hline \multicolumn{7}{|l|}{ Province } \\
\hline Province 3 & 1.00 (ref) & 1.00 (ref) & 1.00 (ref) & 1.00 (ref) & 1.00 (ref) & 1.00 (ref) \\
\hline Province 1 & $\begin{array}{l}0.72(0.20- \\
2.54)\end{array}$ & $\begin{array}{l}0.34(0.10- \\
1.10)\end{array}$ & $\begin{array}{l}0.45(0.17- \\
1.15)\end{array}$ & $\begin{array}{l}0.79(0.27- \\
2.30)\end{array}$ & $\begin{array}{l}0.44(0.14- \\
1.31)\end{array}$ & $\begin{array}{l}0.60(0.28 \\
1.27)\end{array}$ \\
\hline Province 2 & $\begin{array}{l}0.23(0.07- \\
0.82)^{\star}\end{array}$ & $\begin{array}{l}0.14(0.04- \\
0.53)^{\star \star}\end{array}$ & $\begin{array}{l}0.21(0.07- \\
0.66)^{\star \star}\end{array}$ & $\begin{array}{l}0.26(0.08- \\
0.91)^{\star}\end{array}$ & $\begin{array}{l}0.17(0.05- \\
0.60)^{\star \star}\end{array}$ & $\begin{array}{l}0.26(0.11 \\
0.62)^{\star}\end{array}$ \\
\hline Province 4 & $\begin{array}{l}1.27(0.36- \\
4.55)\end{array}$ & $\begin{array}{l}0.73(0.20- \\
2.62)\end{array}$ & $\begin{array}{l}0.63(0.26- \\
1.54)\end{array}$ & $\begin{array}{l}2.04(0.66- \\
6.31)\end{array}$ & $\begin{array}{l}1.02(0.31- \\
3.31)\end{array}$ & $\begin{array}{l}1.09(0.56 \\
2.13)\end{array}$ \\
\hline Province 5 & $\begin{array}{l}0.95(0.30- \\
3.00)\end{array}$ & $\begin{array}{l}0.69(0.21- \\
2.26)\end{array}$ & $\begin{array}{l}0.52(0.22- \\
1.22)\end{array}$ & $\begin{array}{l}1.29(0.45- \\
3.66)\end{array}$ & $\begin{array}{l}1.11(0.36- \\
3.41)\end{array}$ & $\begin{array}{l}0.86(0.48 \\
1.53)\end{array}$ \\
\hline Province 6 & $\begin{array}{l}0.30(0.09- \\
0.97)^{\star}\end{array}$ & $\begin{array}{l}0.25(0.07- \\
0.87)^{\star}\end{array}$ & $\begin{array}{l}0.46(0.15- \\
1.43)\end{array}$ & $\begin{array}{l}0.28(0.09- \\
0.89)^{\star}\end{array}$ & $\begin{array}{l}0.27(0.08- \\
0.88)^{\star}\end{array}$ & $\begin{array}{l}0.57(0.22- \\
1.49)\end{array}$ \\
\hline Province 7 & $\begin{array}{l}0.75(0.23- \\
2.43)\end{array}$ & $\begin{array}{l}0.58(0.17- \\
2.02)\end{array}$ & $\begin{array}{l}0.87(0.34- \\
2.20)\end{array}$ & $\begin{array}{l}0.92(0.30- \\
2.75)\end{array}$ & $\begin{array}{l}0.79(0.25- \\
2.50)\end{array}$ & $\begin{array}{l}1.22(0.61- \\
2.44)\end{array}$ \\
\hline \multicolumn{7}{|l|}{$\begin{array}{l}\text { Wealth } \\
\text { quintile }\end{array}$} \\
\hline Poorest & 1.00 & 1.00 & 1.00 & 1.00 & 1.00 & 1.00 \\
\hline Poorer & $\begin{array}{l}1.58(0.69- \\
3.64)\end{array}$ & $\begin{array}{l}0.87(0.40- \\
1.89)\end{array}$ & $\begin{array}{l}0.91(0.46- \\
1.83)\end{array}$ & $\begin{array}{l}1.13(0.58- \\
2.18)\end{array}$ & $\begin{array}{l}0.83(0.41- \\
1.66)\end{array}$ & $\begin{array}{l}0.99(0.54- \\
1.81)\end{array}$ \\
\hline Middle & $\begin{array}{l}0.91(0.40- \\
2.08)\end{array}$ & $\begin{array}{l}0.97(0.43- \\
2.18)\end{array}$ & $\begin{array}{l}0.76(0.35- \\
1.63)\end{array}$ & $\begin{array}{l}0.63(0.30- \\
1.32)\end{array}$ & $\begin{array}{l}0.91(0.43- \\
1.92)\end{array}$ & $\begin{array}{l}0.74(0.35 \\
1.58)\end{array}$ \\
\hline Richer & $\begin{array}{l}2.19(0.78- \\
6.09)\end{array}$ & $\begin{array}{l}1.11(0.44- \\
2.81)^{(1)}\end{array}$ & $\begin{array}{l}0.85(0.37- \\
1.92)\end{array}$ & $\begin{array}{l}1.25(0.47- \\
3.29)\end{array}$ & $\begin{array}{l}0.97(0.43- \\
2.22)\end{array}$ & $\begin{array}{l}0.81(0.36 \\
1.80)\end{array}$ \\
\hline Richest & $\begin{array}{l}1.17(0.38- \\
3.63)\end{array}$ & $\begin{array}{l}1.10(0.39- \\
3.11)\end{array}$ & $\begin{array}{l}1.39(0.62- \\
3.16)\end{array}$ & $\begin{array}{l}0.74(0.25- \\
2.14)\end{array}$ & $\begin{array}{l}0.80(0.29- \\
2.17)\end{array}$ & $\begin{array}{l}1.07(0.49- \\
2.32)\end{array}$ \\
\hline \multicolumn{7}{|l|}{$\begin{array}{l}\text { Season of } \\
\text { childbirth }\end{array}$} \\
\hline Summer & 1.00 (ref) & 1.00 (ref) & 1.00 (ref) & 1.00 (ref) & 1.00 (ref) & 1.00 (ref) \\
\hline Spring & $\begin{array}{l}0.61(0.29- \\
1.30)\end{array}$ & $\begin{array}{l}0.55(0.26- \\
1.17)\end{array}$ & $\begin{array}{l}1.24(0.63- \\
2.47)\end{array}$ & $\begin{array}{l}0.83(0.34- \\
2.00)\end{array}$ & $\begin{array}{l}0.60(0.30- \\
1.17)\end{array}$ & $\begin{array}{l}1.15(0.55 \\
2.41)\end{array}$ \\
\hline Autumn & $\begin{array}{l}0.81(0.35- \\
1.89)\end{array}$ & $\begin{array}{l}0.86(0.38- \\
1.95)\end{array}$ & $\begin{array}{l}1.63(0.80- \\
3.34)\end{array}$ & $\begin{array}{l}0.96(0.46- \\
2.00)\end{array}$ & $\begin{array}{l}0.89(0.44- \\
1.81)\end{array}$ & $\begin{array}{l}1.54(0.81- \\
2.92)\end{array}$ \\
\hline Winter & $\begin{array}{l}0.72(0.30- \\
1.70)\end{array}$ & $\begin{array}{l}0.91(0.43- \\
1.92)\end{array}$ & $\begin{array}{l}1.82(0.98- \\
3.39)\end{array}$ & $\begin{array}{l}0.83(0.42- \\
1.66)\end{array}$ & 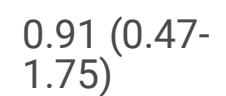 & $\begin{array}{l}1.63 \\
2.85)\end{array}$ \\
\hline
\end{tabular}

Cl-Confidence interval; ref-reference; OPV-Oral Polio vaccine; DTP-Diphtheria, Tetanus, and Pertussis vaccine; Hep B-Hepatitis B vaccine; Hib-Hemophilus influenzae type b vaccine; numbers indicate a dose order; * $p<$ 
$0.05 ; * \star p<0.01 ; p<0.001 ;$ Random effect at PSU level was incorporated to account for survey design.

\section{Figures}

A. A Bacillus-Calmette-Guerin (BCG) vaccine.

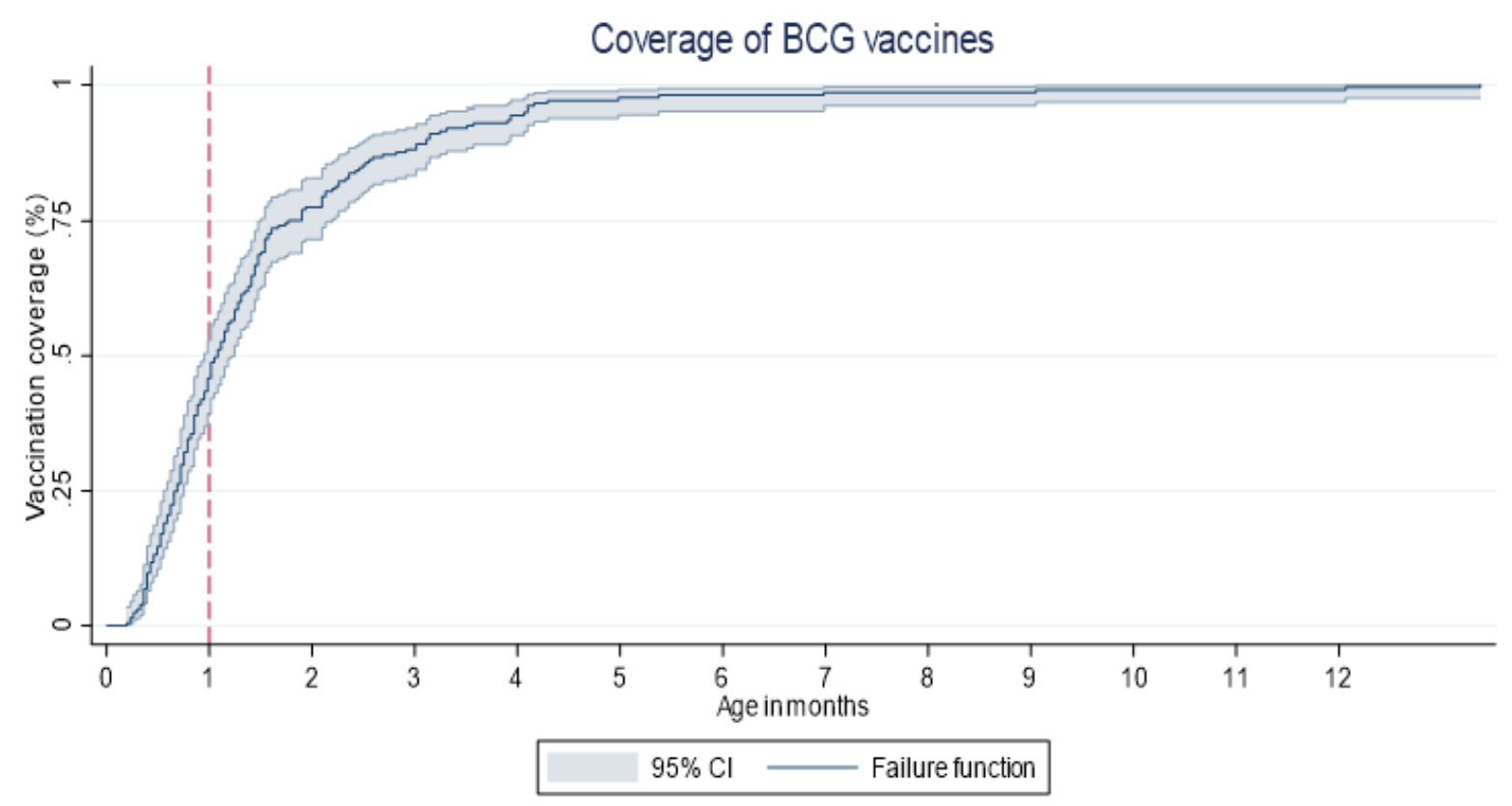

B. Measles, Mumps, and Rubella vaccine, $1^{\text {st }}$ dose (MMR1).

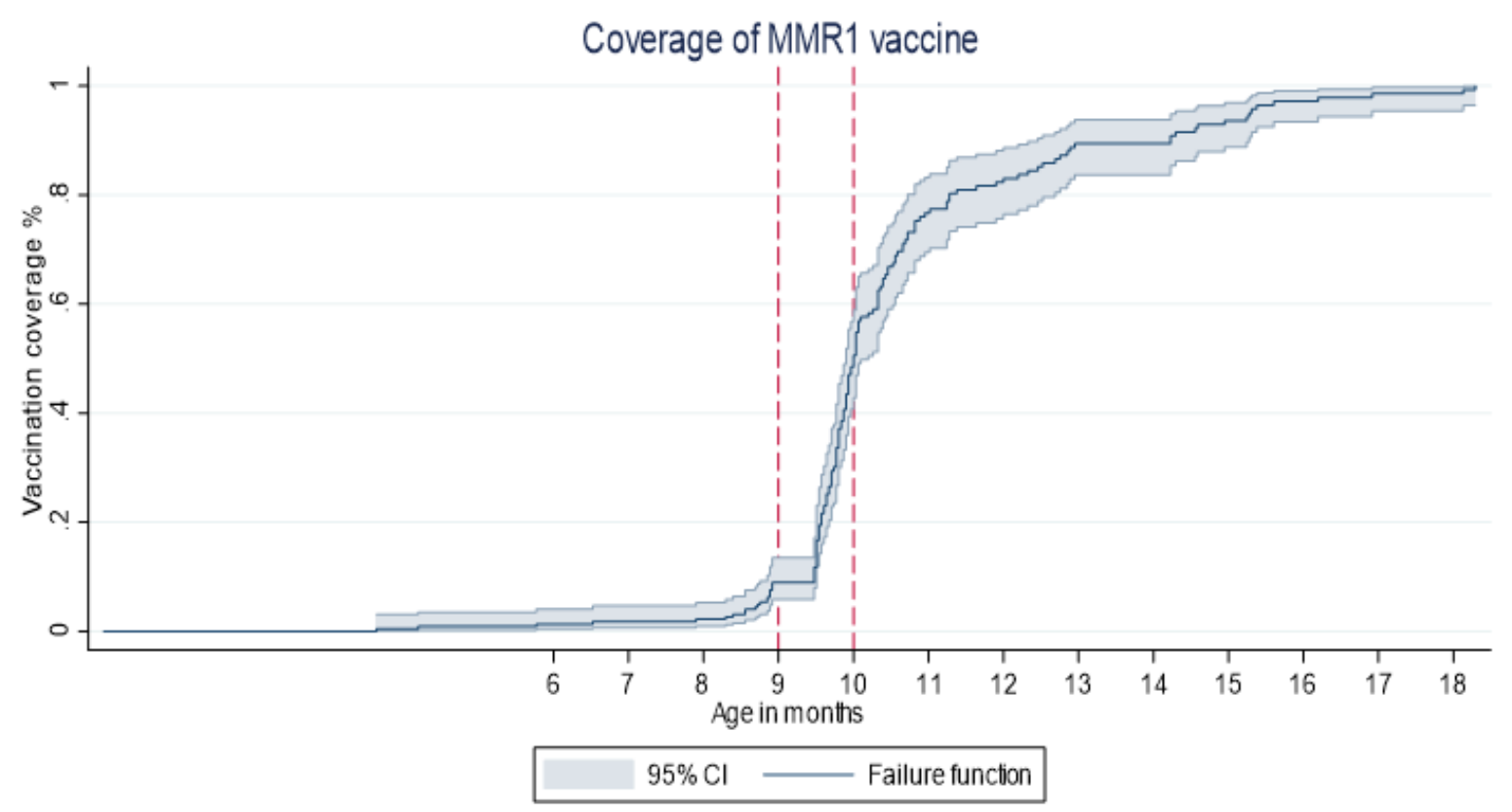

Figure 1 
Age-appropriate coverage of BCG and MMR1 vaccines at national level in Nepal, 2016. Note: BCG-Bacillus Calmette-Guerin vaccine; MMR1-Measles, Mumps, and Rubella vaccine, 1st dose. Cl-Confidence interval

A. Oral polio vaccine (OPV) 1-3 doses.

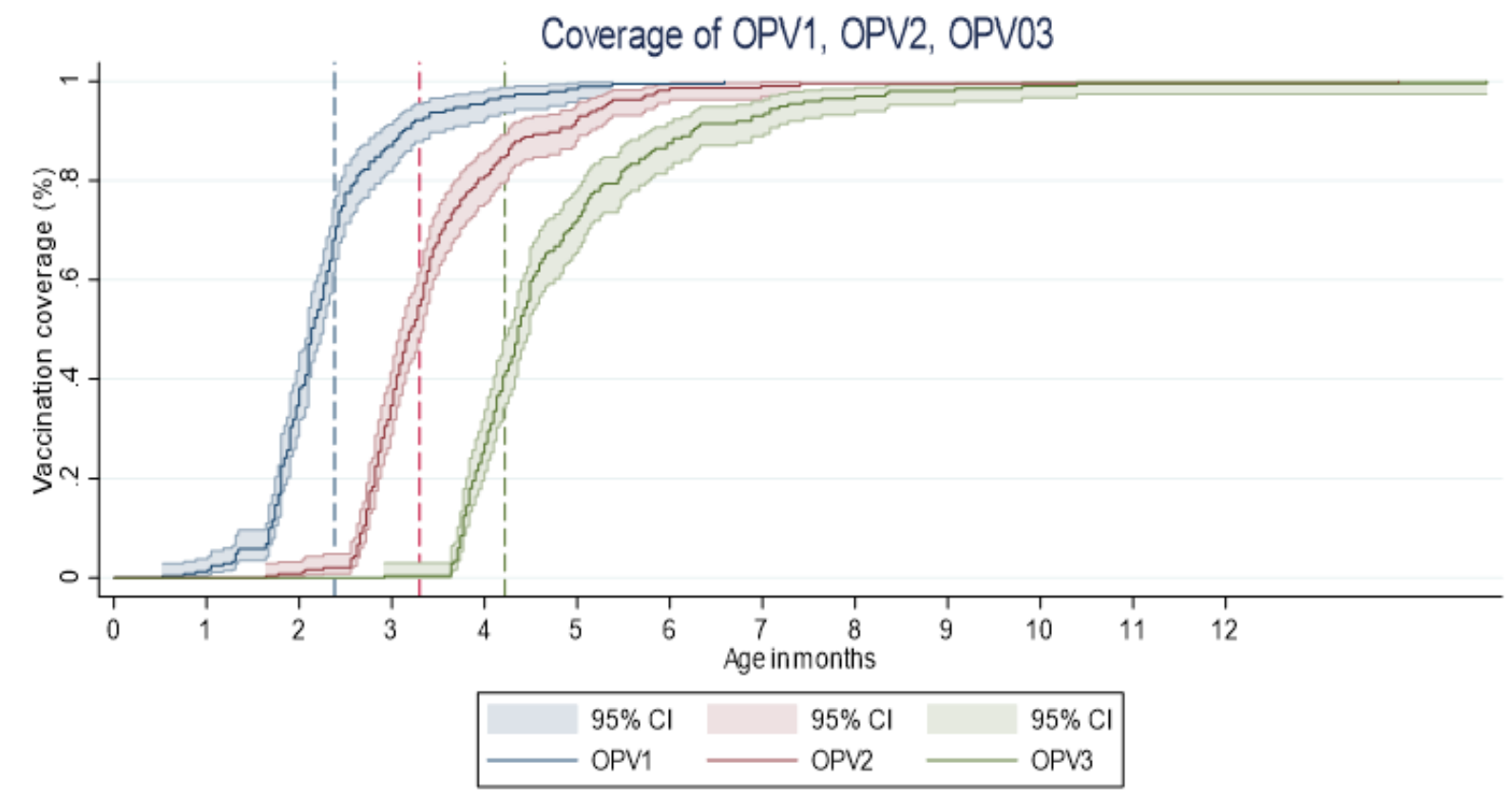

B. Pentavalent vaccine doses (Penta) 1-3 doses.

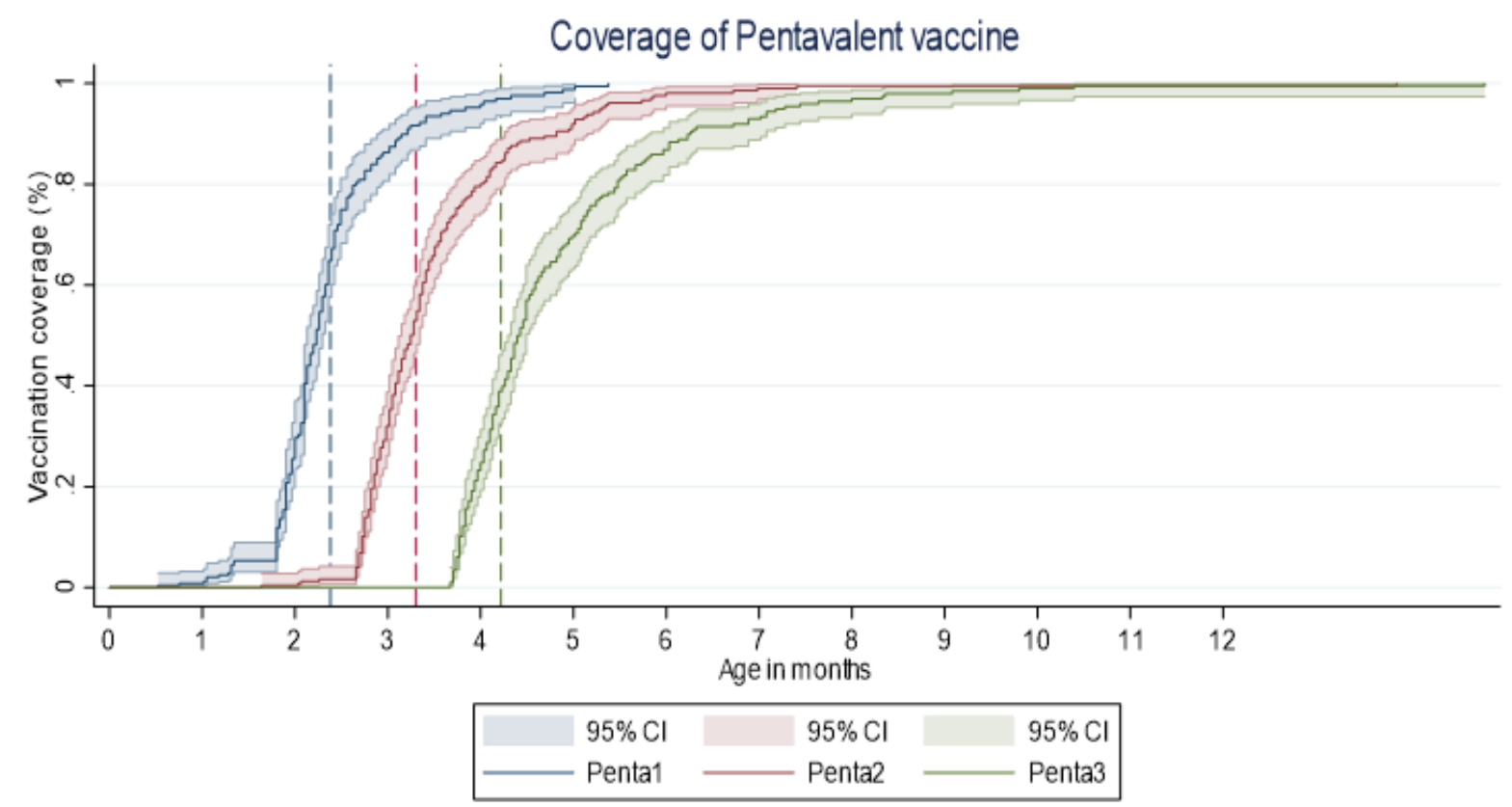

\section{Figure 2}

Age-appropriate coverage of OPV and PE vaccines at national level in Nepal, 2016. Note: OPV-Oral Polio vaccine; Penta1, Penta2, Penta3- Pentavalent vaccines doses 1-3 (DTP-Diphtheria, Tetanus, and Pertussis vaccine; Hep B- Hepatitis B vaccine; Hib-Hemophilus influenzae type b vaccine); Cl-Confidence interval. 
A. Bacillus-Calmette-Guerin (BCG) vaccine.

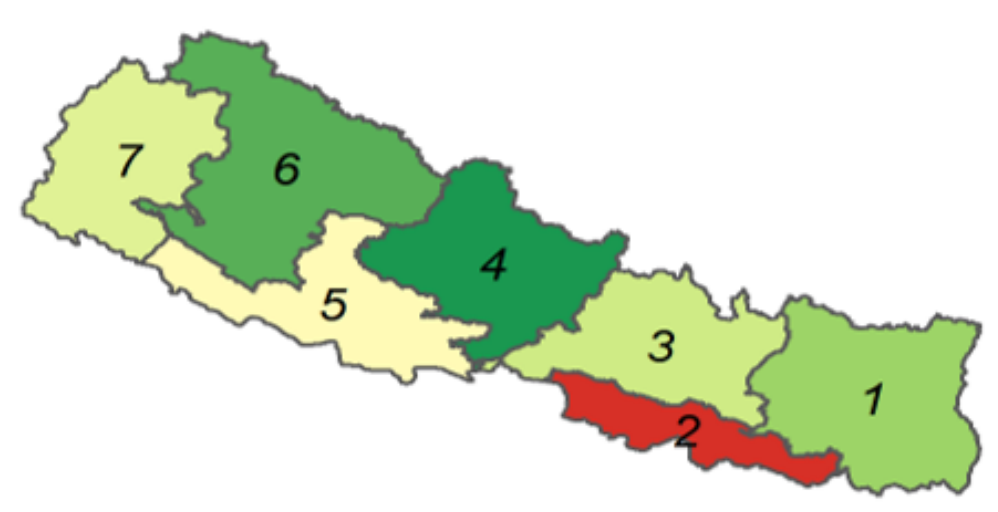

\section{Coverage (\%)}

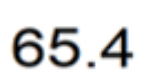

58.1

50.8

43.4

36.1

B. Measles, Mumps, and Rubella vaccine (MMR) $1^{\text {st }}$ dose.

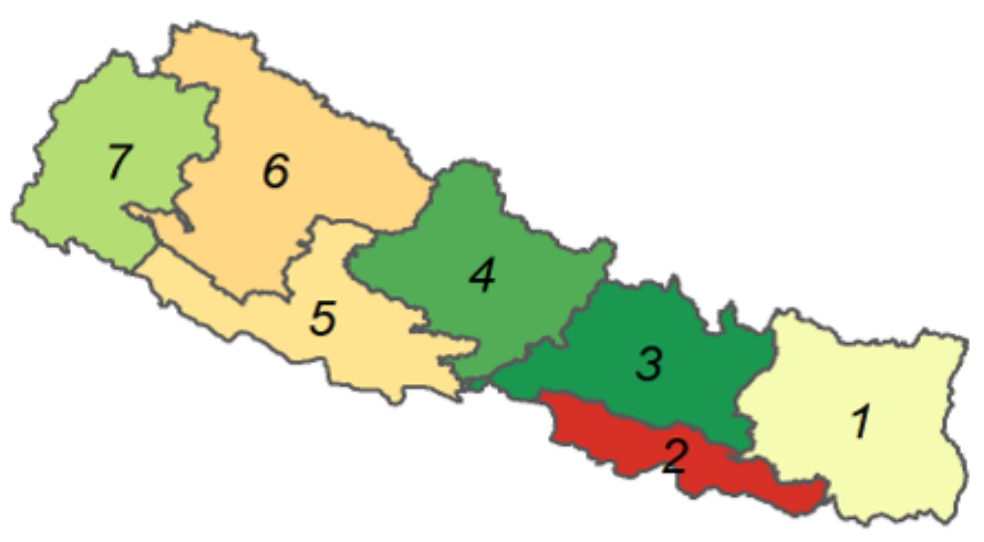

\section{Coverage (\%)}

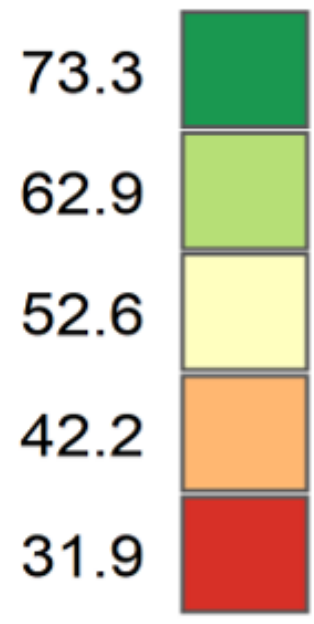

Figure 3

Age-appropriate coverage of BCG and MMR vaccines I at regional level in Nepal, 2016. Note: 1,2,3,4,5,6 and 7 are the respective provinces in Nepal. Note: BCG-Bacillus Calmette-Guerin vaccine; MMR1-Measles, Mumps, and Rubella vaccine, 1 st dose. Cl-Confidence interval. Note: The designations employed and the presentation of the material on this map do not imply the expression of any opinion whatsoever on the part of Research Square concerning the legal status of any country, territory, city or area or of its authorities, or concerning the delimitation of its frontiers or boundaries. This map has been provided by the authors. 
A. Oral polio vaccine $1^{\text {st }}$ dose (OPV1).

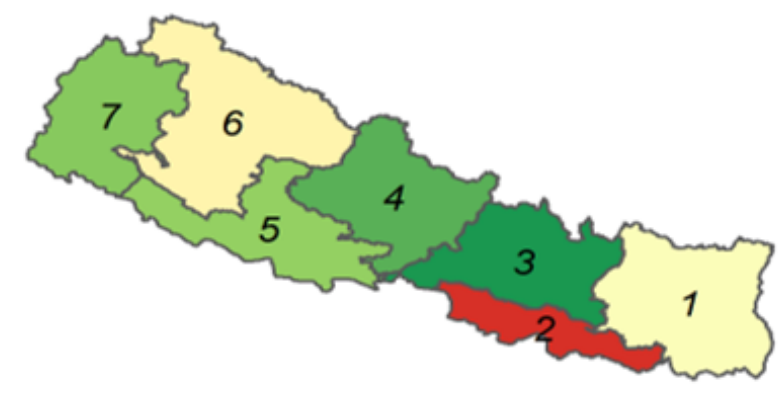

Coverage (\%)

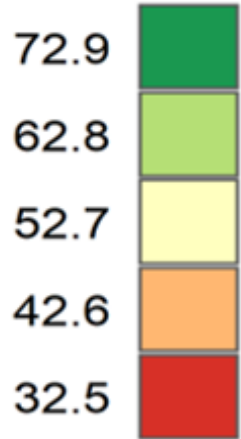

B. Oral polio vaccine $2^{\text {nd }}$ dose (OPV2).

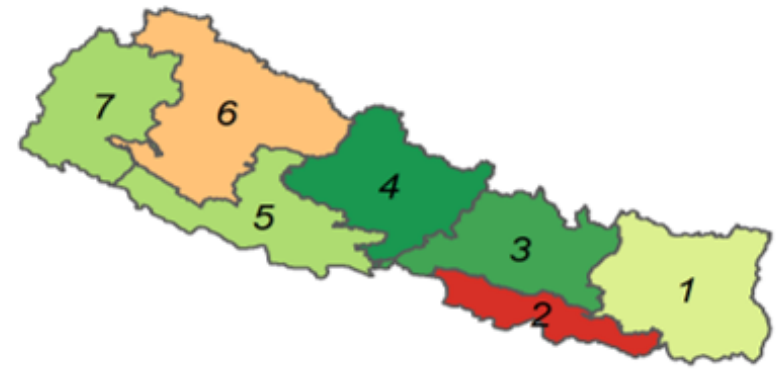

Coverage (\%)

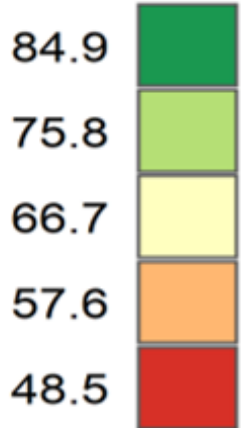

C. Oral polio vaccine $3^{\text {rd }}$ dose (OPV3).

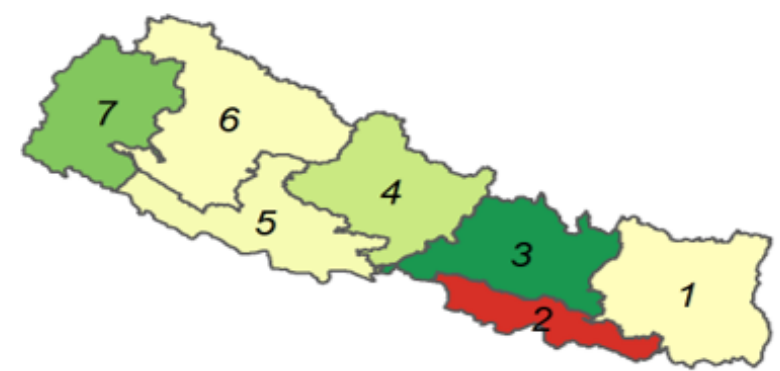

Coverage (\%)

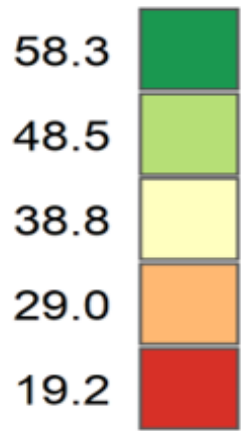

Figure 4

Age-appropriate coverage of Oral polio vaccines doses 1-3 at regional level in Nepal, 2016. Note: 1,2,3,4,5,6 and 7 are the respective provinces in Nepal. Note: The designations employed and the presentation of the material on this map do not imply the expression of any opinion whatsoever on the part of Research Square concerning the legal status of any country, territory, city or area or of its authorities, or concerning the delimitation of its frontiers or boundaries. This map has been provided by the authors. 
A. Pentavalent $1^{\text {st }}$ dose (Penta1).

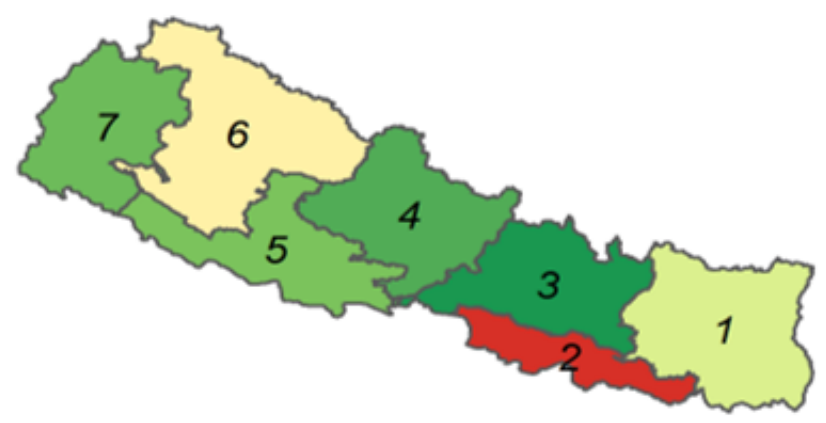

Coverage (\%)

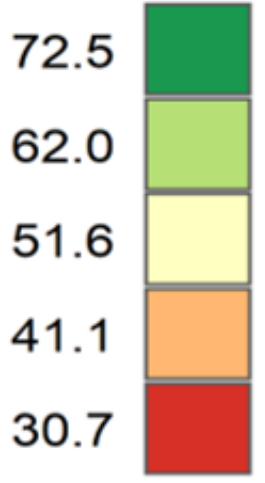

B. Pentavalent $2^{\text {nd }}$ dose (Penta2).

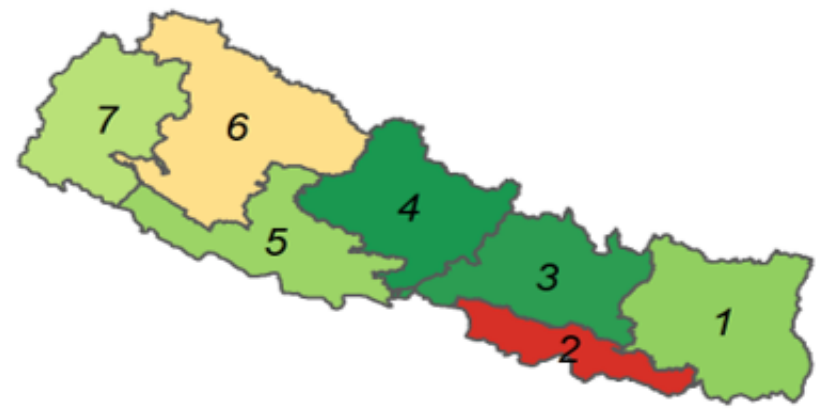

Coverage (\%)

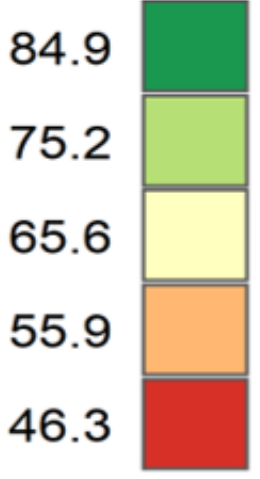

C. Pentavalent $3^{\text {rd }}$ dose (Penta3).

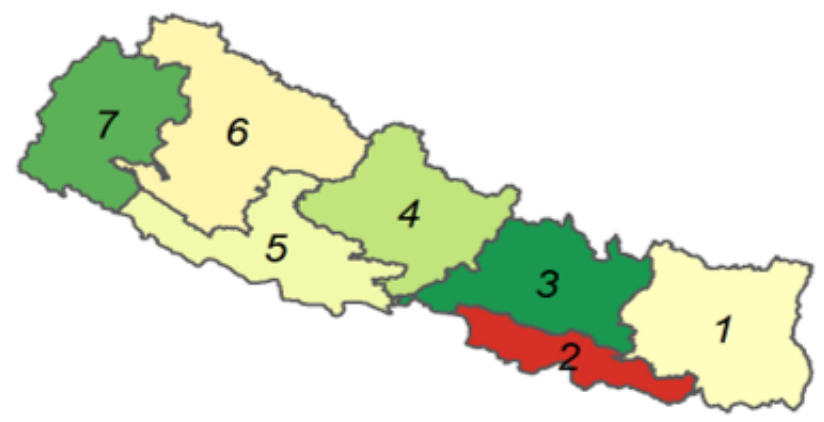

Coverage (\%)

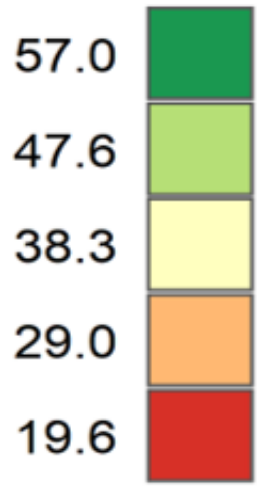

\section{Figure 5}

Age-appropriate coverage of Pentavalent vaccines doses 1-3 at regional level in Nepal, 2016. Note: 1,2,3,4,5,6 and 7 are the respective provinces in Nepal. Note: The designations employed and the presentation of the material on this map do not imply the expression of any opinion whatsoever on the part of Research Square concerning the legal status of any country, territory, city or area or of its authorities, or concerning the delimitation of its frontiers or boundaries. This map has been provided by the authors. 